\title{
Market-driven Derivation of Field Performance Requirements for Conceptual Aircraft Design
}

\author{
N. Dzikus, I. Terekhov, V.Gollnick* \\ German Aerospace Center, Air Transportation Systems, Hamburg, 21079, Germany \\ J. Hartmann ${ }^{\dagger}$ \\ German Aerospace Center, Institute of System Architectures in Aeronautics, Hamburg, 21129, Germany
}

\begin{abstract}
An approach to derive a take-off field length for the initial specification of a new aircraft design is introduced in this paper. Based on a passenger demand forecast the runway lengths of the origin and destination airports are analyzed. The physical lengths of the runways are corrected by airports' elevation and reference temperatures. The approach to derive airport reference temperatures on air transport system level is described in more detail. For an exemplary range of flight distances and the corresponding market, runway lengths are determined and corrected. Consequently the percentage of passenger demand can be described as a function of runway lengths. The example illustrates that airports' elevation and reference temperature significantly affect the percentage of passenger demand that can be accommodated by an aircraft design for a given take-off field length.
\end{abstract}

\section{Nomenclature}

TLAR
ICAO
TOFL
$D L R$
$A C S T$
IATA
$M E T A R$
$O D$
$P D F$
$C D F$
ISA
$E U R O C O N T R O L$
$A I S$
$A T S$
$l_{R w y, S L}$
$l_{R w y, C o r r}$
$h_{A D}$
$T_{A R T}$
$T_{A D, I S A}$
$T_{a}$
$T_{m}$

$T L A R$

$I C A O$

TOFL

$D L R$

$A C S T$

$I A T A$

$M E T A R$

$O D$

$P D F$

$C D F$

$I S A$

$A I S$

$A T S$

$l_{R w y, S L}$

$l_{R w y, C o r r}$

$T_{A D, I S A}$

$T_{m}$
Top-Level Aircraft Requirement

International Civil Aviation Organization

Take-Off Field Length

Deutsches Zentrum fuer Luft- und Raumfahrt

Airport Capacity Scenario Tool

International Air Transport Association

Meteorological Aviation Routine Weather Report

Origin-Destination

Probability Density Function

Cumulative Density Function

International Standard Atmosphere

European Organisation for the Safety of Aviation

Aeronautical Information System

Air Transportation System

Runway length, physical

Runway length, corrected

aerodrome elevation

aerodrome reference temperature

airport temperature at ISA conditions

monthly mean of average daily temperature (hottest month)

monthly mean of the maximum daily temperature(hottest month)

\footnotetext{
*Air Transportation Systems, Blohmstr. 20, 21079 Hamburg.

${ }^{\dagger}$ Aircraft Design \& System Integration, Hein-Sass-Weg 22, 21129 Hamburg.
} 


\section{Introduction}

Top-level aircraft requirements (TLARs) form the initial specification for every new aircraft design. "In civil aviation the specification of a new aircraft type is generally drawn up by the manufacturer. Airlines are usually more content to evaluate projects offered to them for use on their own network, though in few cases they themselves have taken the initiative and written the specification which they felt was required." (see Ref.1, S.10). The most relevant TLARs include among others: ${ }^{2}$

- payload (number of passengers, weight or freight)

- range

- speed

- take-off and landing performance

- design service goal (number of flights, total flight hours, years of service)

- maintenance

- inspection intervals

- noise

In this paper we focus on the TLAR "Take-Off Performance" or more specific the "Take-Off Field Length" (TOFL) of an new aircraft design. According to Ref. 3, the TOFL has a significant effect on wing loading and thrust-to-weight-ratio and therefore impacts aircraft design remarkable.

For definition of the TOFL there are two starting points thinkable: ${ }^{1}$

- The aircraft is optimized for other flight phases such as cruising flight and take-off performance is a consequence of the resulting design.

- The runway performance of the new aircraft is adapted to existing airport infrastructure.

In the past the infrastructure generally was adapted to the performance of the aircraft. As can be seen in Fig. 1 the development in aircraft size and propulsion technology required the extension of existing runways. Since the 1970s the maximum runway length at London-Heathrow did not increase and is approximately $12800 \mathrm{ft}(3900 \mathrm{~m})$ in length. Since 2003 Amsterdam Schiphol airport comprises of the "Polderbaan" (runway designators: 18R-36L) with a length of approx. 12500ft (3800m) (not shown in Fig. 1). As will be shown later in this paper there are hardly any airports that comprise of runways longer than $4000 \mathrm{~m}$. There are few exceptions with unsurprisingly Denver International Airport having the longest runway of approx. 16000ft (4900m).

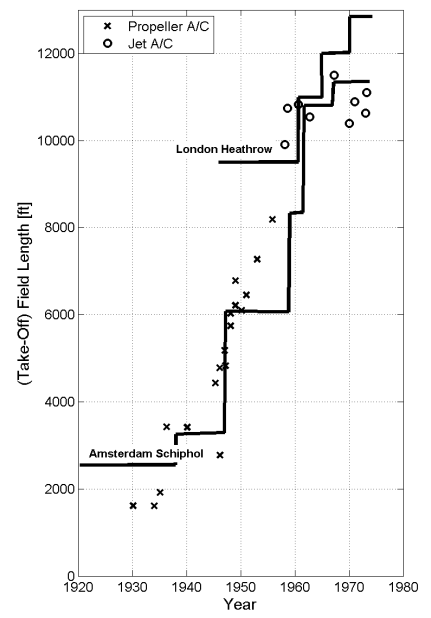

Figure 1. Developement of take-off field length requirements for propeller and jet aircraft and the development of field lengths at Amsterdam Schiphol airport and London-Heathrow airport over time (adapted from Ref.1, p.14). 
The method described herein deducts the TLAR "Take-Off Field Length" from existing airport infrastructures, namely existing runway lengths. Therefore a database with airport key data is used and opposed to a forecast of future passenger demand on specific origin-destination (OD) pairs for a given design range. Thereby a "market-tailored" TOFL is deducted. Additionally, to take local meteorological and geographical conditions into account, the physical runway lengths are corrected by airport elevation and airport reference temperature. As a result of this analysis the percentage of passenger demand that can be accommodated for the market specified is opposed to corrected (temperature and elevation) runway lengths. This result can help to answer the question: How much demand can be accommodated for a given TOFL?

The structure of this paper is as follows: In the second paragraph "Method" the general approach to correct the physical runway length by airport elevation and airport reference temperature is described (subsection A) as well as the databases and tools used to derive passenger demand and physical runway lengths (subsection B). The calculation of the airport reference temperature on a global basis is described in more detail in subsection C. In paragraph III "Application" a specific use-case for the derivation of the TLAR "TOFL" is described. The paper ends with a "Conclusion" and an "Outlook" (paragraph IV and V, respectively).

\section{Method}

\section{A. Runway Length Correction}

The approach taken for runway length correction is based on a publication of the International Civil Aviation Organization (ICAO). ${ }^{4}$ It takes elevation, temperature and slope into account. In this paper we focus on the parameters elevation and temperature. If the runway length required for take-off at sea level in standard atmospheric conditions is known, the corrected runway length (without taking slope into account!) can be calculated by:

$$
l_{R w y, C o r r}=\left[\left(l_{R w y, S L} \cdot 0.07 \cdot \frac{h_{A D}}{300}\right)+l_{R w y, S L}\right] \cdot\left[\left(T_{A R T}-T_{A D, I S A}\right) \cdot 0.01+1\right]
$$

Since the runway length for take-off at sea-level is to be defined by the definition of the TLAR, the equation must be adapted:

$$
l_{R w y, S L}=\frac{l_{R w y, C o r r}}{\left[\left(0.07 \cdot \frac{h_{A D}}{300}\right)+1\right] \cdot\left[\left(T_{A R T}-T_{A D, I S A}\right) \cdot 0.01+1\right]}
$$

Where $T_{A D, I S A}$ is a function of airport elevation:

$$
T_{A D, I S A}=-0.0065^{\circ} \mathrm{C} / \mathrm{m} \cdot h_{A D}+15
$$

If we now assume that the corrected runway length $l_{R w y, C o r r}$ is equal to the physical runway length of the airport under consideration, the runway length at sea level $\left(l_{R w y, S L}\right)$ is the TOFL that has to be defined as the TLAR in order to allow the aircraft to start from this specific airport.

Runway elevation can easily be determined through existing databases. There are two different approaches for the calculation of the airport reference temperature. ICAO claims the following: 4

"The aerodrome reference temperature shall be the monthly mean of the daily maximum temperatures for the hottest month of the year (the hottest month being that which has the highest monthly mean temperature). This temperature shall be averaged over a period of years."

In Ref. 5 it is stated:

"Airport reference temperature is defined as the monthly mean of average daily temperature (Ta) for the hottest month of the year plus one-third the difference of this temperature (Ta) and the monthly mean of the maximum daily temperature (Tm) for the same month of the year.", i.e.:

$$
T_{A R T}=T_{a}+\frac{T_{m}-T_{a}}{3}
$$

In this paper we go after the second approach. 


\section{B. Passenger Demand Forecast \& Airport Database}

As mentioned in the introduction the aim is to determine runway lengths for a variety of airports worldwide. Therefore basic airport information must is provided through an airport database. For airport specific studies the Airport Capacity Scenario Tool (ACST) was developed by the DLR (Deutsches Zentrum fuer Luft- und Raumfahrt) that allows editing of airport-specific data over time. This information includes basic data like International Air Transport Association (IATA) and ICAO-codes, airport elevation and more precise information like runway threshold coordinates. The airport elevation can directly be readout of the database. Physical runway lengths of the runways can be determined through the runway thresholds coordinates. The calculation of the airport reference temperature is a more complex task and will be described in subchapter B.

Passenger demand is given by a DLR tool called "aircast". The basic information needed is passenger demand between origin-destination (OD) pairs. This demand is estimated by the aircast-tool on the basis of socio-economic indicators and then translated to flight routes on a global level. Thereby the tool allows to extract demand for a defined range of flight distances. For further details see Ref. 8. For this study we investigated two different scenarios of the passenger forecast, namely a "Point-to-Point"-scenario and a "Hub-and-Spoke"-scenario.

\section{Airport Reference Temperature Calculation}

The general workflow for the calculation of aerodrome reference temperatures is shown in Fig. 2. The user defines the input parameters, including the year for which the analysis shall be conducted, the airport database with necessary information (here limited to the ICAO Codes) and parameters for $T_{A R T}$ calculation like the definition of the daytime and the number of maximum gaps tolerated in the temperature for interpolation.

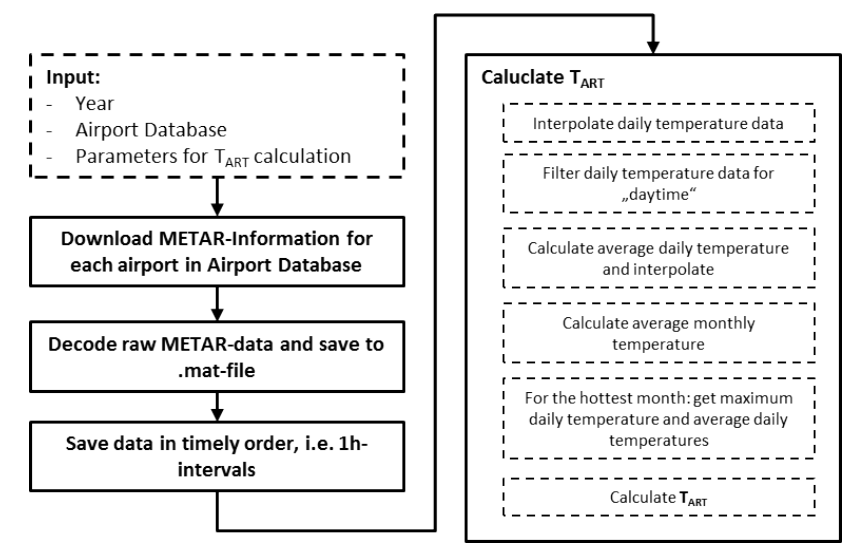

Figure 2. Flow Chart describing the basic steps to derive airport reference temperatures from METAR data.

The data source for the calculation of the aerodrome reference Temperature is Meteorological Aviation Routine Weather Report (METAR) provided by Ref. 6. It contains information starting from 2003 for a variety of airports worldwide. The raw METAR information is decoded so that daily data can be downloaded in the format shown in Fig. 3 (example for Munich Airport (EDDM).

A computer script reads out the METAR information "temperature", next to other meteorological information such like wind direction, wind speed, dewpoint, ceiling, visibility. In a next step this information is saved in timely order. Normally METAR information is updated two times per hour. We use 1h-intervals for the calculation of the airport reference temperature. Therefore, if two METAR-datasets are available for a specific hour, the average of these temperatures is used.

In some cases there are gaps in the temperature data. These gaps are filled by interpolation if the maximum value of gaps is not exceeded (e.g. a user-defined value of 6). For Munich Airport (EDDM) the hourly temperatures for $24 \mathrm{~h}$ periods for two exemplary days are shown in Fig. 4 together with interpolated datapoints. In Fig. 5 the temperature profiles of each day of the whole year 2010 are depicted. In the definition of the airport reference temperature it is mentioned that the "average daily temperature" must be used for the calculation of the airport reference temperature. We assumed that this excludes night times 


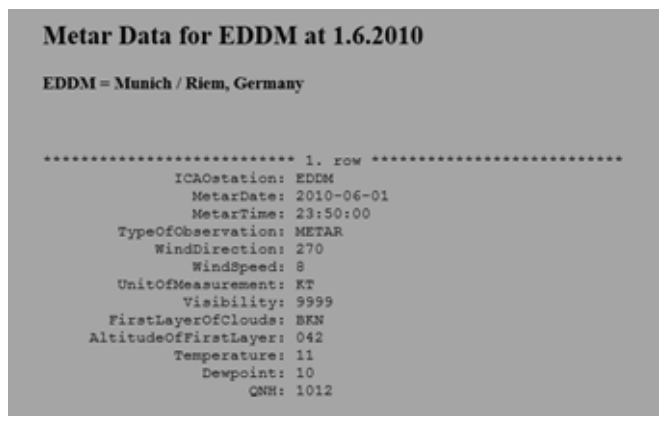

Figure 3. Exemplary METAR information from Munich Airport (EDDM) from the $1^{\text {st }}$ June 2010.

and therefore considered the possibility to define a user-selected "daytime". In the example of Fig. 5 this daytime is between 8:00 to 20:00, represented by the red dotted lines. Consequently the temperature values during this period of the day will be used for further calculations.

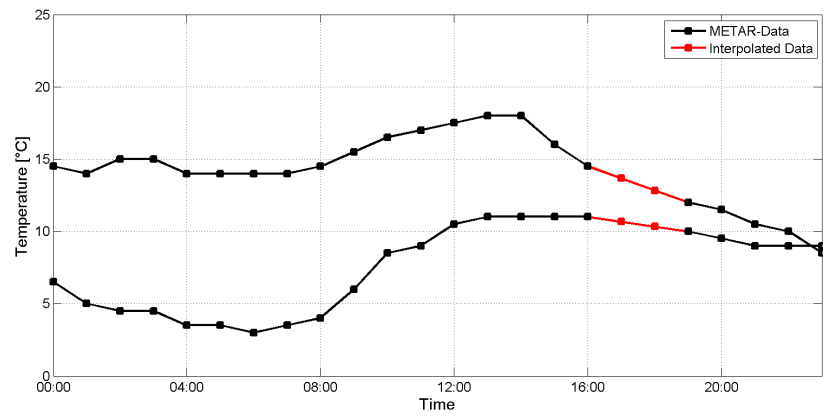

Figure 4. Exemplary distribution of hourly temperatures over the course of a day (22 $2^{\text {nd }}$ June 2010 and $15^{\text {th }}$ November 2010) at Munich Airport (EDDM).

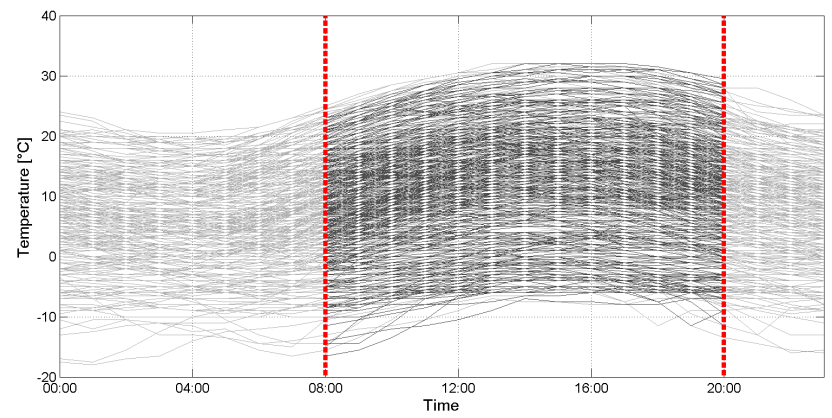

Figure 5. Exemplary distribution of hourly temperatures over the course of a day at Munich Airport (EDDM) for the year 2010.

The average daily temperatures are calculated on the basis of the hourly temperatures of the selected daytime-period. The outcome is depicted in Fig. 6 (black solid line) together with interpolated data (red solid line). The extent to which interpolation is possible is also user-defined, e.g. a maximum number of 10 days (or 10 gaps respectively) is chosen for the example shown. The calculation of aerodrome reference temperature shall be based on temperatures of the "hottest month of the year". We use a 30-day moving average to determine the hottest 30-days period in a year. This is also shown in Fig. 6 (dashed blue line), together with the hottest 30 days period (margined by the red dashed lines). In the example shown the hottest month of the year 2010 for EDDM would be between $23^{\text {rd }}$ of June $\left(174^{\text {th }}\right.$ day of the year) and $23^{r d}$ of July (204 ${ }^{\text {th }}$ day of the year).

Maximum daily temperatures of the hottest month of the year are shown for this example in Fig. 7 (black solid line) together with the mean value of these temperatures (blue dashed line). 


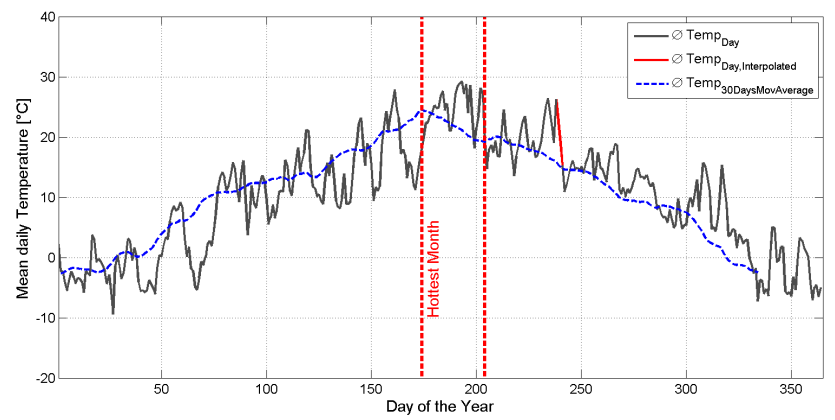

Figure 6. Mean daily temperatures at Munich Airport (EDDM) for the year 2010 (black line) and average monthly temperature as 30-days Moving-Average (blue dashed line).

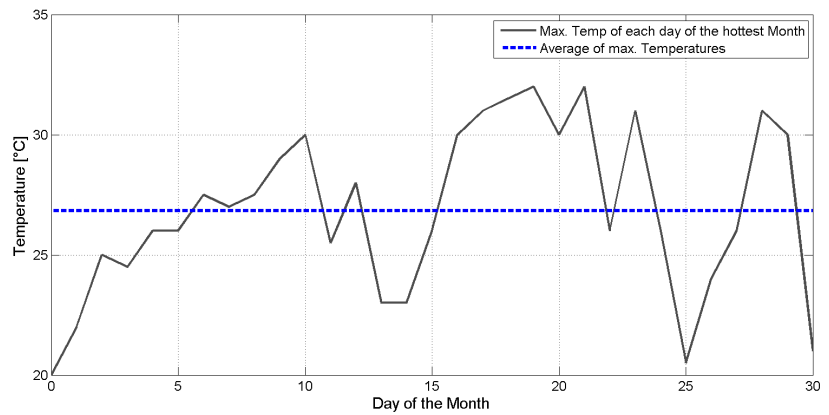

Figure 7. Maximum daily temperatures of the hottest month of the year 2010 at Munich Airport (EDDM) and average of maximum temperatures (blue dashed line).

For the example of Munich Airport and the year selected (2010) the aerodrome reference temperature is:

$$
T_{A R T}=24,6^{\circ} \mathrm{C}+\frac{26,8^{\circ} \mathrm{C}-24,6^{\circ} \mathrm{C}}{3}=25,4^{\circ} \mathrm{C}
$$

In Table 1 the calculated airport reference temperatures for selected European airports are presented (validation data from Ref. 7). The difference for most of the airports listed is less than 10 percent. Again, it is noted that the calculation of the $T_{A R T}$ is based on data of the year 2010 and the approach described in Ref. 5. This is a possible explanation for the differences that occur. For Lisbon airport (LPPT) the difference is the biggest, i.e. 5, $5 \mathrm{C}$. In Ref. 7 it is noted that this temperature is based on the month August in comparison to the moving average approach used here. Additionally we only took "daily" temperatures into account, i.e. temperatures that were locked between $8 \mathrm{am}$ to $8 \mathrm{pm}$, to exclude lower temperatures during the night. The results for a 24-hour period are listed in the last column of Table 1. It can be seen that the inclusion of the nighttime does not affect the airport reference significantly. Most of the values for $T_{A R T}$ only decrease by $1-2^{\circ} C$. 
Table 1. Modelled airport reference temperatures validated against published data for selected European airports.

\begin{tabular}{|r|c|c|c|c|c|c|}
\hline \multicolumn{1}{|c|}{ Country } & Airport & ICAO-Code & IATA-Code & $T_{A R T}(A I P)$ & $T_{A R T, 12 h}$ & $T_{A R T, 24 h}$ \\
\hline Greenland & Nuuk & BGGH & GOH & not published & 12,2 & 11,6 \\
\hline Greenland & Kangerlussuaq & BGSF & SFJ & 15,6 & 15,5 & 13,6 \\
\hline Finland & Helsinki & EFHK & HEL & 23,0 & 25,8 & 24,1 \\
\hline Finland & Ivalo & EFIV & IVL & 19,0 & 18,0 & 17,1 \\
\hline United Kingdom & Aberdeen & EGPD & ABZ & 16,0 & 17,1 & 16,0 \\
\hline United Kingdom & Shannon & EINN & SNN & 20,2 & 18,3 & 17,1 \\
\hline United Kingdom & London (Heathrow) & EGLL & LHR & 20,0 & 23,6 & 21,8 \\
\hline Germany & Frankfurt & EDDF & FRA & 24,2 & 27,2 & 25,1 \\
\hline Germany & Munich & EDDM & MUC & 24,0 & 25,2 & 23,1 \\
\hline France & Paris & LFPG & CDG & 24,7 & 25,1 & 23,8 \\
\hline France & Paris,Orly & LFPO & ORY & 28,8 & 25,4 & 23,9 \\
\hline France & Bordeaux & LFBD & BOD & 25,6 & 26,2 & 24,5 \\
\hline Italy & Rome & LIRF & FCO & 28,3 & 29,1 & 27,2 \\
\hline Spain & Madrid & LEMD & MAD & 34,0 & 31,8 & 30,2 \\
\hline Spain & Barcelona & LEBL & BCN & 29,0 & 27,0 & 26,3 \\
\hline Portugal & Lisbon & LPPT & LIS & 24,2 & 29,7 & 27,9 \\
\hline
\end{tabular}

A graphical representation of the airport reference temperatures is shown in Fig. 9(a) for all airports for which the corresponding data and data quality was available. In this case there are 1490 of 3741 airports for which the airport reference temperature could be determined (see Fig. 9(a)). Consequently, for the majority of the airports in the airport database the corresponding METAR data was not available or data quality was insufficient. In order to cope with this limitation a regression formula is derived that estimates airport reference temperatures for which $T_{A R T}$ could not be calculated with the existing data points by using the geographical location, namely the Latitude. The regression curve, the corresponding regression formula as well as the datapoints are shown in Fig. 10.

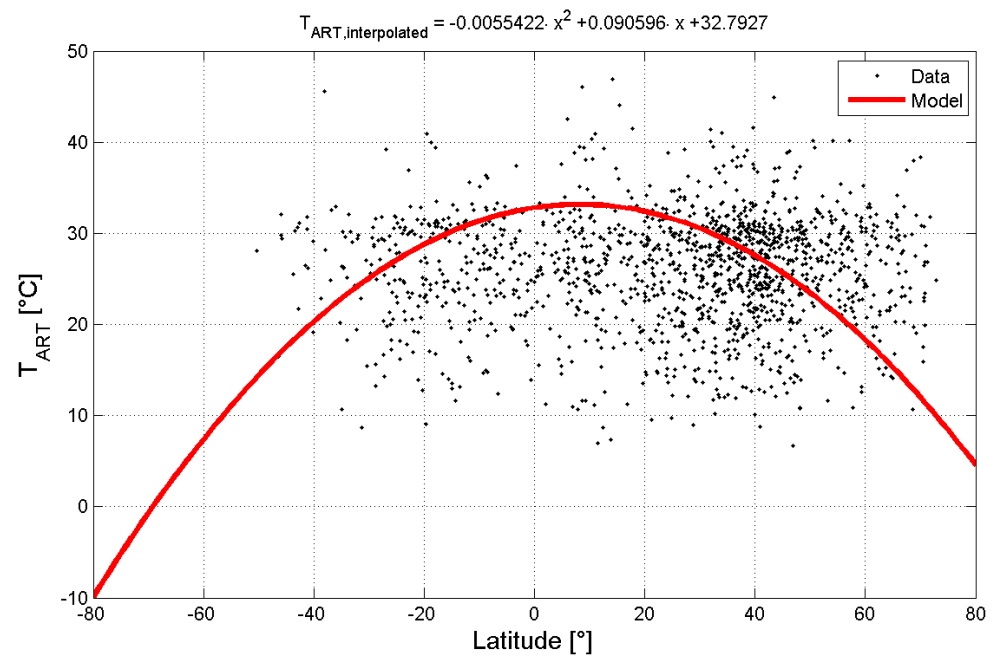

Figure 8. Simple approach for the interpolation of airport reference temperatures based on airports' Latitudes.

It is noted that this is a rather rough estimation of real conditions since temperatures are influenced by a large number of factors. This issue will be discussed in the Outlook of this paper. The distribution of airport reference temperatures for all airports in the database is shown in Fig. 9(b). 


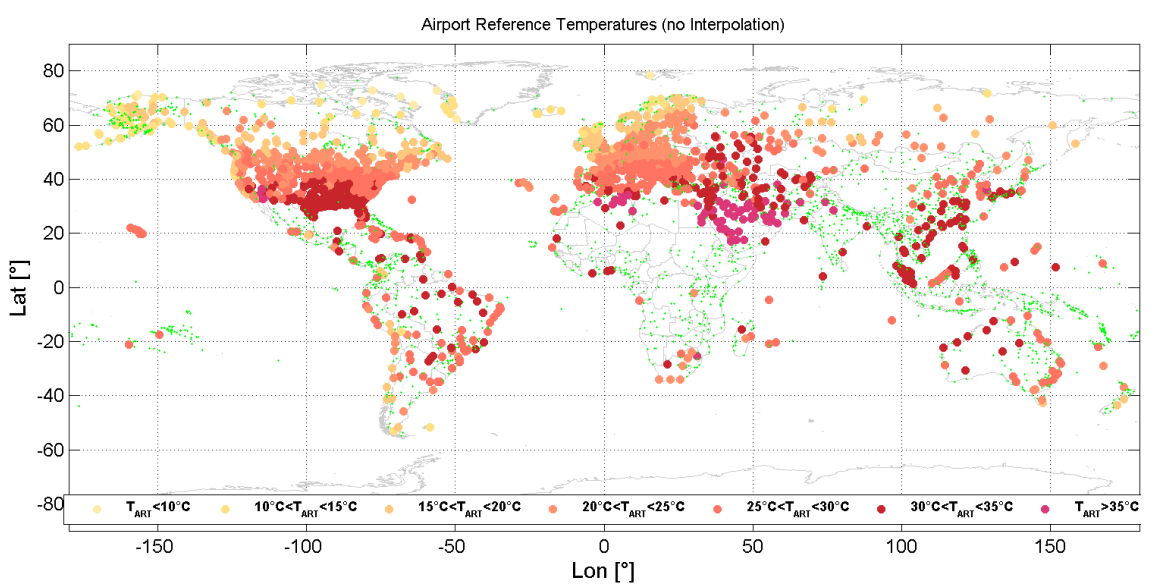

(a) Graphical representation of $T_{A R T}$ for airports with valid METAR data (1490 airports).

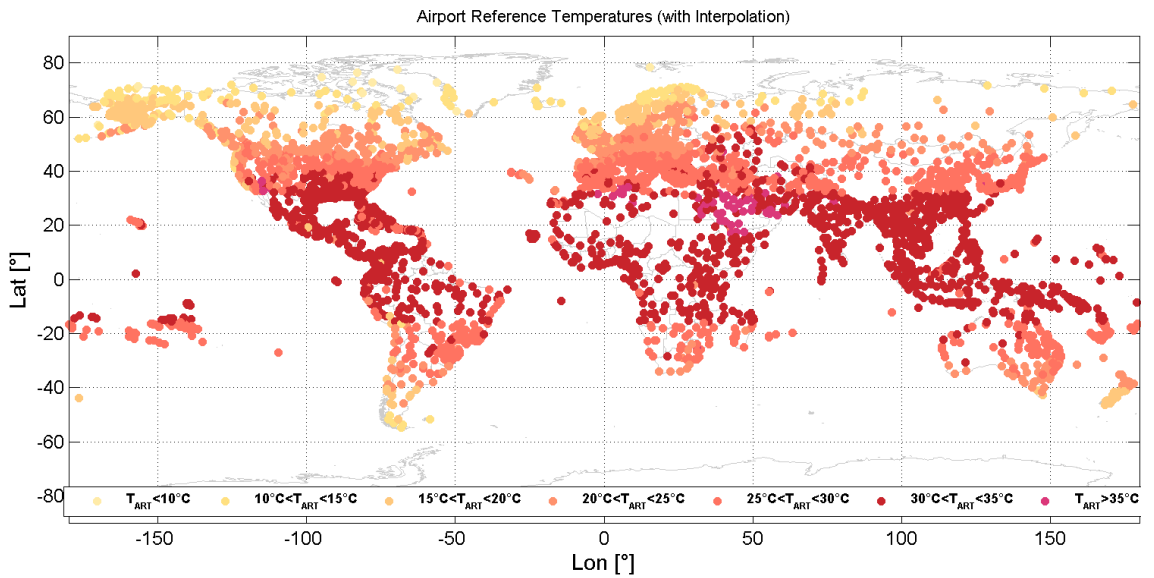

(b) Graphical representation of $T_{A R T}$ for airports with valid METAR data and interpolated data points (3741 airports).

Figure 9. Graphical representation of $T_{A R T}$ of airports with valid METAR data (Fig. 9(a)) and interpolated data $(9(b))$.

\section{Workflow}

In Fig. 10 the general workflow is depicted that shows how the different elements that are described in the previous subsections are integrated to derive market-driven TOFL:

- Input Parameters: There are input parameters to be defined by the user, i.e. the year of the forecast (as an input for the demand database as well as for the selection of the infrastructure scenario), the distance range (as an input for the demand database and the corresponding selection of routes), the minimum number of passengers (as an input for the demand database and filtering of lucrative routes), and the network type (as described in subsection B).

- Read/Filter Demand Data: In this step the selected forecast scenario (i.e. "Hub-and-Spoke", "Pointto-Point") is filtered according to the selected design range and minimum number of passengers. As a result only routes that are within the selected range and provide the minimum number of passengers are used for further analysis.

- Read Airport Infrastructure Data: As described in subsection B, the ACST-tool is capable of defining different infrastructure scenarios. According to the year selected by the user, the corresponding scenario is used for further analysis.

- Determine max. Rwy Length per Airport (physical): In this step the runway lengths for the airports of interest are computed. 
- Calculate Airport Reference Temperatures: Airport reference temperatures are computed as described in subsection C.

- Determine max. Rwy Length per Airport (corrected): In this step the physical runway lengths are corrected by temperature and elevation as described in subsection A.

- Determine min. Rwy Length per OD-Pair (physical/corrected): For the market targeted, i.e. the ODpairings listed in the forecast scenario, the minimum runway length for each OD pair is determined.

- Determine Percentage of Pax for different Rwy Lengths (physical/corrected): In the final step the runway lengths are compared to passenger volumes. As a result the percentage of passenger volume for a selected TOFL can be derived.

In the following chapter some exemplary results for a specific use-case are shown.

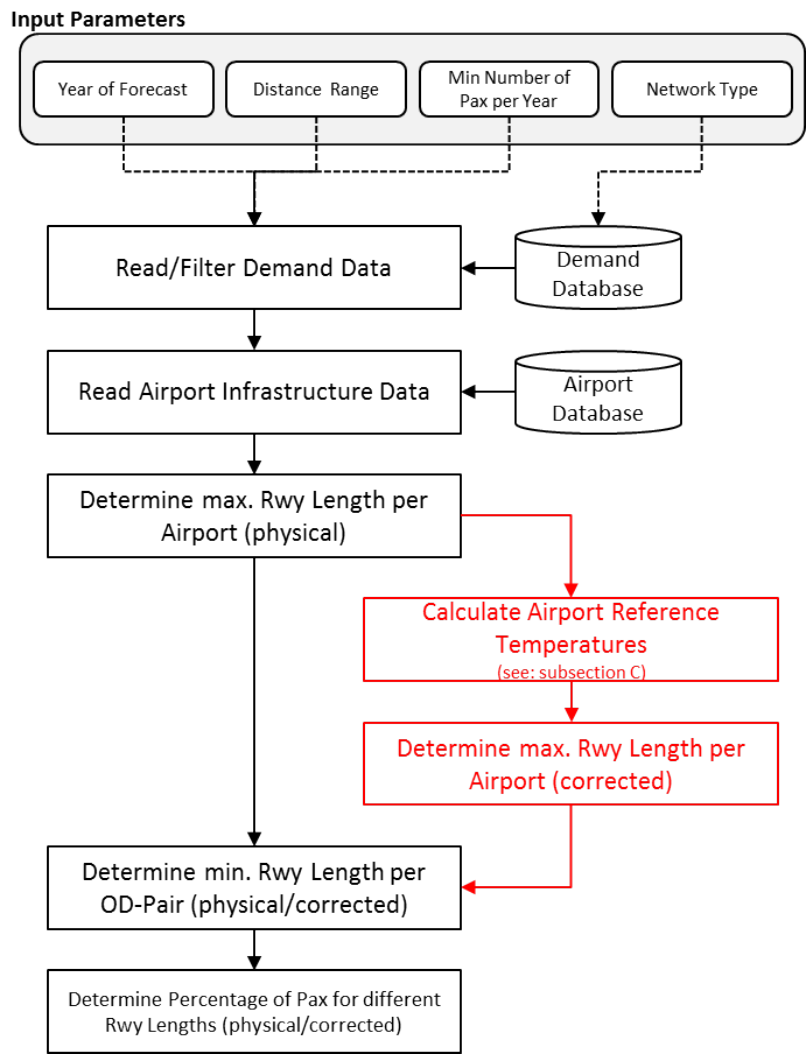

Figure 10. Flowchart for the derivation of market-driven take-off field lengths.

\section{Application}

As stated in the introduction the method for runway length correction is applied to derive a "markettailored" TLAR for the take-off field length. The basis of the analysis is a forecast of passenger demand between different city pairs or OD pairs. The forecast is derived by the aforementioned aircast-model. The model enables to define specific design ranges and the corresponding forecasted demand that results from OD-pairs within this range. As an example the OD pairs for a design range of $6000-10000 \mathrm{~km}$ is shown in Fig. 11. The year of the forecast is 2032. In total there is a potential passenger volume of around 280 million passengers on 4581 routes, starting from 765 airports. 


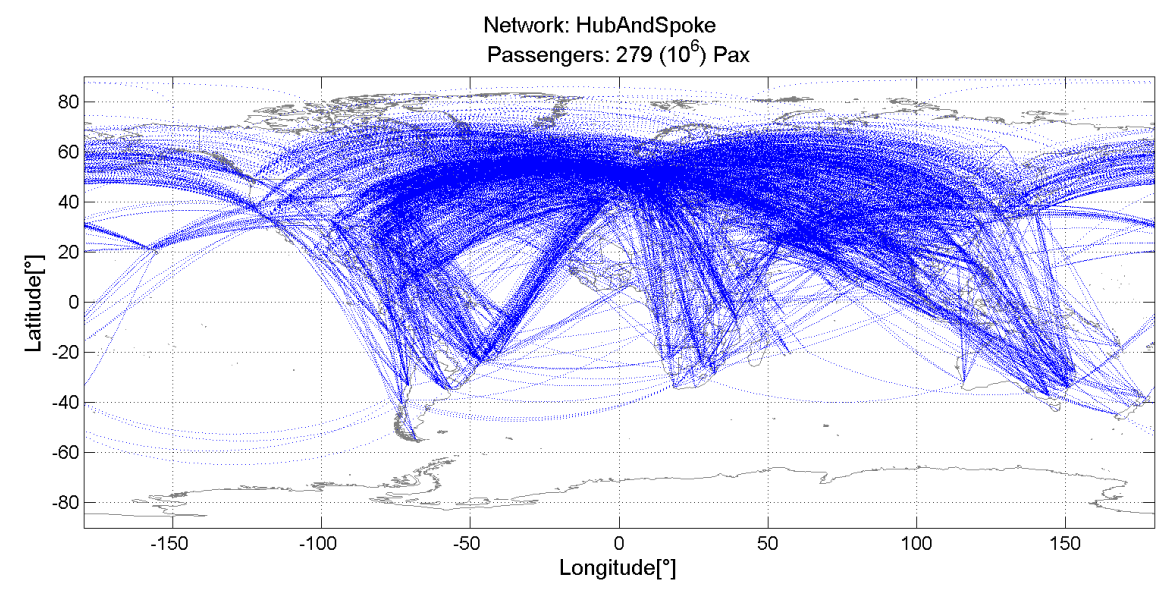

Figure 11. Forecasted Origin-Destination Pairs with flight distances between 6000-10000km for the year 2032.

For the airports relevant for this market the runway lengths are extracted from the airport database. For airports with more than one runway we limit the analysis on the longest runway in this study. The probability density function for the 6000-10000km market and the corresponding cumulative density function are shown in Fig. 12. The thin black graphs represent the functions if only the physical runway lengths are analyzed, i.e. without any corrections with respect to airports elevation and airport reference temperatures, whereas the wider black line represents the functions as a result of the corrected runway lengths.

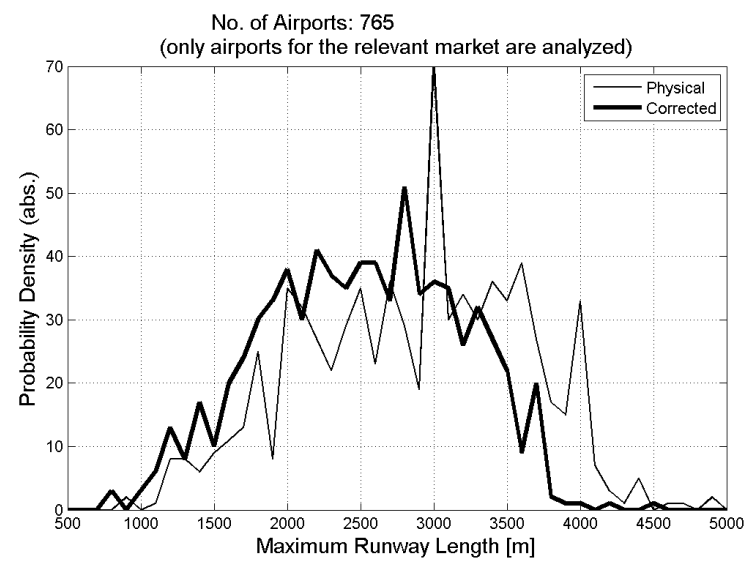

(a) Probability density functions (PDF) for runway lengths (physical and corrected).

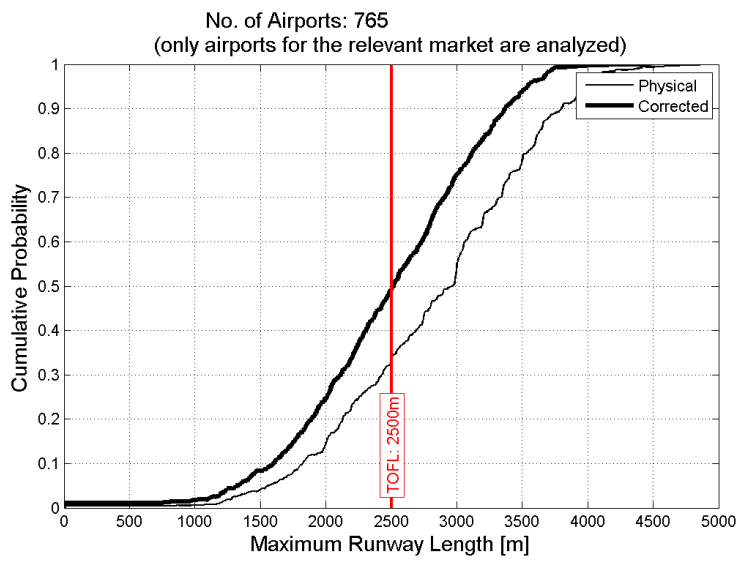

(b) Cumulative density functions (CDF) for runway lengths (physical and corrected).

Figure 12. PDFs (Fig. 12(a)) and CDFs (Fig. 12(b)) of the runway lengths for the specified market (physical and corrected).

Results of the PDFs show that the distribution of physical runway lengths (with an obvious peak at $3000 \mathrm{~m}$ ) is shifted considerably to shorter runway lengths when corrected by airport elevation and reference temperature on basis of Eq. 3. In the CDF a TOFL of $2500 \mathrm{~m}$ is sketched in. It shows that about $65 \%$ of the runways considered could be served if meteorological and geographical aspects are neglected. In the case of corrected runway lengths only about $50 \%$ of the runways can be served.

Since information about expected passenger volumes on routes is available, the percentage of total passenger demand as a function of the runway length is depicted in Fig. 13. Thereby, for a given TOFL the percentage of total passenger demand can be determined that the new aircraft is capable to serve. As an example a TOFL of $2500 \mathrm{~m}$ is depicted in Fig. 13 that results in approximately $73 \%$ of the passenger volume. This percentage decreases in the case of the corrected runway lengths to $61 \%$. In other words: if the market share of the future aircraft has to be increased, the TOFL must be decreased accordingly. For example: by decreasing the TOFL by $500 \mathrm{~m}$, i.e. to $2000 \mathrm{~m}$, the percentage of passengers that could be accommodated increases to about $80 \%$. It is noted that this only applies if no airport-related infrastructural enhancement 
(i.e. runway extensions) are considered.

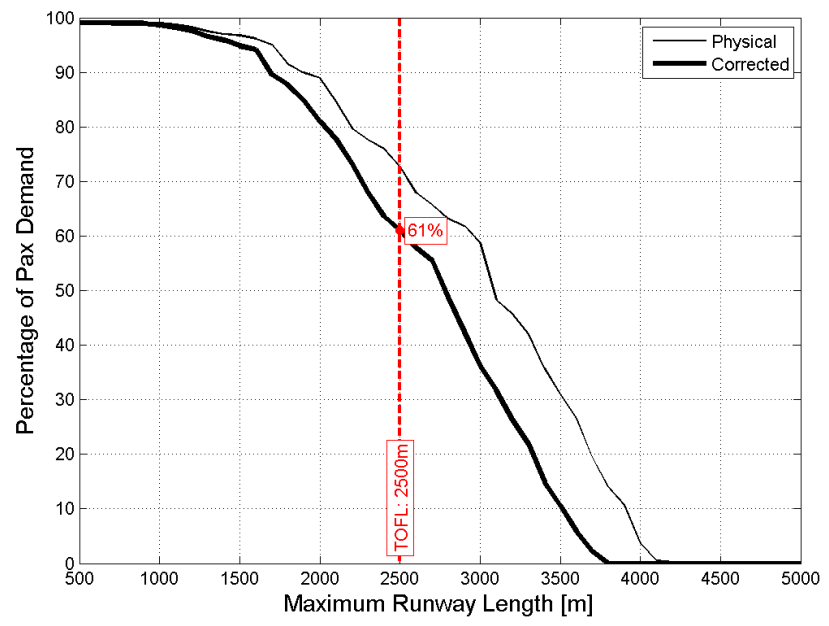

Figure 13. Percentage of passenger demand as a function of runway length (physical and corrected).

\section{Conclusion}

A method to derive the TOFL for aircraft design specifications (TLAR) that is based on existing on existing airport infrastructures is introduced. In order to cope with the fact that aircraft take-off performance is highly dependent on airport constraints, i.e. airport elevation and temperature, a preliminary approach for the correction of physical runway lengths, published by ICAO, is used. Based on forecast passenger demand, the physical runway length of the relevant market are corrected by airports elevation and reference temperatures. The general process how airport reference temperatures are estimated is described in more detail and shows that the results obtained can be used for further analyses. For the example of flight distances between $6000-10000 \mathrm{~km}$ and the corresponding OD pairs the runway lengths are readout from databases and corrected. As a result the percentage of passenger demand for the market envisaged is calculated as a function of corrected runway lengths. This information forms the basis for the deduction of the TLAR TOFL. The results show that the influence of the parameters "elevation" and "airport reference temperature" significantly affects runway lengths.

\section{Outlook}

There are some aspects mentioned in this paper that can be investigated in more detail or that should be improved:

It is not clear which assumptions are made by the ICAO that led to equation Eq. 1 for the correction of runway lengths. A discussion of the influence of the factors "elevation" and "airport reference temperature" could be initiated by analyzing take-off performance data of existing aircraft types.

The database used to obtain raw METAR data should be supported by other meteorological information sources to increase the number of airports with valid data and to decrease the number of airports where $T_{A R T}$ has to be interpolated.

For airports or geographical locations for which interpolation is necessary, e.g. because data quality is not sufficient or simply not available, the interpolation method should be elaborated. The approach used here is very simple and neglects many influencing factors. A possible way for improvement could be spatial interpolation as described in Ref. 9.

It is assumed that the future aircraft is operated in the current ATS infrastructure. Often airports adapt their infrastructure, e.g. extend their runways, depending on the aircraft types that will be operated by airlines (see e.g. Ref. 1, pp.14). In this case airport database, or the runway lengths at airports respectively, might change over time. The ACST tool is capable to define such scenarios. The corresponding impact on TOFL could be investigated in follow-up studies. 


\section{References}

${ }^{1}$ E. Torenbeek, Synthesis of Subsonic Airplane Design, Delft University Press, Delft, Netherlands, 1982.

${ }^{2}$ U.P. Breuer, Commercial Aircraft Composite Technology, Springer, 2016.

${ }^{3}$ E. Anton, T.Lammering, R. Henke, Fast estimation of top-level aircraft requirement impact on conceptual aircraft designs, $10^{\text {th }}$ AIAA Aviation Technology, Integration, and Operations (ATIO) Conference, Fort Worth, Texas, 13.-15. September 2010.

${ }^{4}$ International Civil Aviation Organization, Aerodrome Design Manual - Part 1: Runways, URL: https://www. bazl.admin.ch/dam/bazl/de/dokumente/Fachleute/Flugplaetze/ICAO/icao_doc_9157_aerodromedesignmanual-part1.pdf. download.pdf/icao_doc_9157_aerodromedesignmanual-part1.pdf, accessed: 16. November 2016.

${ }^{5}$ N.J. Ashford, S.A. Mumayiz, P.H. Wright, Airport Engineering - Planning, Design, and Development of $21^{\text {st }}$-Century Airports, $4^{\text {th }}$ Edition, John Wiley \& Sons, 2011.

${ }^{6}$ N.N., METAR-Archiv, Verband der Angehrigen des koordinierten Wetterdienstes (VAKW), URL: http://www.vakw.ch/, last accessed: 15. November 2016.

${ }^{7}$ N.N., European AIS Database, Eurocontrol, URL: https://www.ead.eurocontrol.int/publicuser/public/pu/login.jsp, accessed: 14. November 2016.

${ }^{8}$ R. Ghosh, K. Klker, I. Terekhov, Future Passenger Air Traffic Modelling: A theoretical Concept to integrate Quality of Travel, Cost of Travel and Capacity Constraints, $19^{\text {th }}$ World Conference of the Air Transport Research Society (ATRS), Singapur, 2.-4.July 2015.

${ }^{9}$ O.E. Tveito, G.A. Dalsbø, Estimation of Airport Reference Temperatures, Norwegian Meteorological Institute, URL: http://met.no/filestore/note9_2005.pdf, accessed: 14. July 2016. 